\title{
BMI
}

\section{HIV mortality and infection in India: estimates from nationally representative mortality survey of 1.1 million homes}

\begin{abstract}
Prabhat Jha, professor and director, ${ }^{1}$ Rajesh Kumar, professor and head, ${ }^{2}$ Ajay Khera, joint director, ${ }^{3}$ Madhulekha Bhattacharya, professor and head, ${ }^{4}$ Paul Arora, PhD candidate, ${ }^{1}$ Vendhan Gajalakshmi, director, ${ }^{5}$ Prakash Bhatia, professor, ${ }^{6}$ Derek Kam, PhD candidate, ${ }^{1}$ Diego G Bassani, scientist, ${ }^{1}$ Ashleigh Sullivan, MPH student, ${ }^{1}$ Wilson Suraweera, research fellow, ${ }^{1}$ Catherine McLaughlin, research fellow, ${ }^{1}$ Neeraj Dhingra, additional director, ${ }^{3}$ Nico Nagelkerke, professor $^{1,7}$ on behalf of the Million Death Study Collaborators
\end{abstract}

'Centre for Global Health Research, Li Ka Shing Knowledge Institute, St Michael's Hospital, Dalla Lana

School of Public Health, University of Toronto, Toronto, Canada M5C1N8

${ }^{2}$ School of Public Health, Postgraduate Institute of Medical Education and Research, Chandigarh-160012, India

${ }^{3}$ National AIDS Control Organization, Ministry of Health and Family Welfare, Government of India, Janpath, New Delhi, 110001, India

${ }^{4}$ National Institute of Health and Family Welfare, Munirka, New Delhi, 110067

${ }^{5}$ Epidemiological Research Centre, Kilpauk Garden Colony, Chennai, 600 010, Tamil Nadu, India

${ }^{6}$ Osmania Medical College, Koti City, Hyderabad, Andhra Pradesh, India

${ }^{7}$ Department of Community Medicine, United Arab Emirates University, P O Box 17666 Al Ain United Arab Emirates

Correspondence to: $\mathrm{P}$ Jha prabhat.jha@utoronto.ca

Cite this as: $B M J$ 2010;340:c621 doi:10.1136/bmj.c621

\section{ABSTRACT}

Objective To determine the rates of death and infection from HIV in India.

Design Nationally representative survey of deaths.

Setting 1.1 million homes in India.

Population 123000 deaths at all ages from 2001 to 2003.

Main outcome measures HIV mortality and infection.

ResultsHIV accounted for $8.1 \%$ (99\% confidence interval $5.0 \%$ to $11.2 \%$ ) of all deaths among adults aged

25-34 years. In this age group, about $40 \%$ of deaths from HIV were due to AIDS, $26 \%$ were due to tuberculosis, and the rest were attributable to other causes. Nationally, HIV infection accounted for about 100000 (59000 to $140000)$ deaths or $3.2 \%$ (1.9\% to $4.6 \%$ ) of all deaths among people aged $15-59$ years. Deaths from HIV were concentrated in the states and districts with higher HIV prevalence and in men. The mortality results imply an HIV prevalence at age $15-49$ years of $0.26 \%(0.13 \%$ to $0.39 \%)$ in 2004, comparable to results from a 2005/6 household survey that tested for HIV (0.28\%). Collectively, these data suggest that India had about 1.4-1.6 million HIV infected adults aged $15-49$ years in 2004-6, about $40 \%$ lower than the official estimate of 2.3 million for 2006 . All cause mortality increased in men aged 25-34 years between 1997 and 2002 in the states with higher HIV prevalence but declined after that. HIV prevalence in young pregnant women, a proxy measure of incidence in the general population, fell between 2000 and 2007. Thus, HIV mortality and prevalence may have fallen further since our study.

Conclusion HIV attributable death and infection in India is substantial, although it is lower than previously estimated.

\section{INTRODUCTION}

In India, and most other countries, heterosexual transmission accounts for most HIV infections. ${ }^{1}$ Transmission from female sex workers to male clients, and then to these clients' regular partners, is the most common chain of infection. ${ }^{2-5}$
Because clinical testing is uncommon, India, like most low income countries, uses "sentinel surveillance" of anonymous, unlinked testing of pregnant women to monitor trends in HIV among the general population. ${ }^{67}$ We have previously reported that the incidence of HIV, measured indirectly through prevalence in young pregnant women aged 15-24 years, fell by nearly 50\% in selected states between 2000 and $2007 .{ }^{89}$ However, sentinel surveillance, although useful to estimate trends, cannot estimate reliably the absolute prevalence of HIV in India or HIV attributable mortality. ${ }^{10}$

The government of India officially revised its estimate of the prevalence of $\mathrm{HIV}$ in adults aged 15-59 years from 5.1 million to 2.5 million (range 2.03.1 million) in 2006. ${ }^{112}$ The revision was partly because a nationally representative HIV prevalence survey in 2005/6 found the prevalence at ages 15-49 years to be less than half of that estimated earlier from sentinel surveillance. ${ }^{1213}$ The earlier sentinel surveillance data were used by the World Health Organization to estimate that between 270000 and 630000 deaths from HIV occurred in 2003. ${ }^{14}$ WHO subsequently reduced this to 127000 deaths in 2004 on the basis of the results of the 2005/6 survey. ${ }^{15}$

However, the 2005/6 survey of HIV faced methodological problems, ${ }^{2}$ and its estimate of HIV prevalence has not been confirmed. Thus, direct, independent estimates of HIV attributable mortality would be important to confirm the relations between new and prevalent infections and mortality and also to plan treatment services. ${ }^{16}$ In this paper, we provide estimates of HIV attributable mortality from the first ever nationally representative survey of deaths, ${ }^{17}$ carried out in 1.1 million homes. We also estimate the prevalence of HIV infection from HIV attributable mortality, the reverse of the $\mathrm{WHO}$ procedure, and relate this to trends in HIV infection.

\section{METHODS}

We combined direct estimates of deaths from AIDS from a nationally representative mortality survey ${ }^{17}$ 
with indirect estimates of the maximal proportions of deaths from diseases other than AIDS (notably tuberculosis) that may have HIV infection as the underlying cause of death. We applied a maximal observed excess of HIV attributable mortality from tuberculosis in 19902000 in selected urban hospitals ${ }^{18}$ to selected non-AIDS diseases in our mortality survey. We compared our estimates of mortality from AIDS to the prevalence of HIV infection among pregnant women and adults testing at voluntary counselling and testing sites. ${ }^{6}$ Table 1 shows the population, years, sample size, and variables extracted from the various data sources.

\section{Nationally representative mortality survey}

The Registrar General of India is responsible for the Sample Registration System, in which several thousand small areas are chosen, on the basis of the preceding census, to be nationally representative of India's population. ${ }^{17}$ The 1993 sample covered 1.1 million homes in 6671 areas (4436 rural and 2235 urban areas, with an average of 165 homes or about 1000 people per area). Since 2001, 800 Sample Registration System supervisors have visited all homes where a death had been recorded to collect information that would help to identify the underlying cause of death. ${ }^{171920}$ The average time elapsed between death and field interview was 2.1 (range 0.5-3.1) years. Details of the field methods, quality control checks, and validation results have been published. ${ }^{1720-25}$

We defined Andhra Pradesh, Karnataka, Maharashtra, and Tamil Nadu in south India and Manipur and Mizoram in northeast India as high HIV states on the basis of the prevalence of HIV in pregnant women. ${ }^{1}$ The total population of the high HIV states in 2005 was 192 million for ages 15-49, or 30\% of India's total population for this age group, and these states together account for about $75 \%$ of $\mathrm{HIV}$ infections reported nationally. ${ }^{6}$ Injecting drug use dominates transmission in the northeast states ${ }^{6}$; although this complicates interpretation of HIV trends in pregnant women, it has little impact on estimation of mortality from HIV. Low HIV states are the remainder of India (470 million adults aged 15-49 years; 70\% of India's total). Owing to operational problems, Nagaland ( $1 \%$ of total deaths in India) could not be surveyed and was excluded from the analyses.
Field "verbal autopsy" with central medical adjudication of causes of death

Most of the estimated 10 million annual deaths in India occur without medical certification at the time of death. ${ }^{26}$ Thus, alternative methods to determine the underlying cause of death are needed. ${ }^{17}$ We used an enhanced version, "RHIME" (representative, resampled, routine household interview of mortality with medical evaluation), ${ }^{1719-21}$ of a "verbal autopsy" technique (fig 1). The RHIME method relies on the assumption that most causes of death have distinct symptoms and signs that can be recognised, recalled, and reported by household members or associates of the deceased to a trained, non-medical field worker. We trained nearly 900 non-medical field interviewers (800 Sample Registration System supervisors, 100 resampling staff) to interview living household relatives of the deceased to record the symptoms, signs, and key circumstances leading to death, including a descriptive narrative in the local language of the main events and treatments. Two independent trained physicians examined scanned images of the written field reports to assign the causes of death, using a web based management system. ${ }^{20} \mathrm{~A}$ random sample of about $5 \%$ of the areas was re-surveyed independently by field staff who had received more training than the Sample Registration System supervisors and who reported directly to us. Using the re-sampled deaths at age 1559 as the reference diagnosis, the sensitivity and specificity were $80 \%$ and $99 \%$ for the 10 re-sampled deaths from AIDS and 65\% and 98\% for the 117 re-sampled deaths from tuberculosis.

The specific criteria for deaths from AIDS used by the physicians came from validation studies in Africa, ${ }^{162728}$ a cohort study of HIV infected adults not taking antiretroviral treatment in Mumbai, ${ }^{29}$ and clinical studies in India. ${ }^{30-32}$ The key symptoms for deaths from AIDS included prolonged (more than one month) fever, diarrhoea, or cough; mouth sores or patches; swelling of lymph nodes; and recent weight loss. If the two physicians did not agree on the three digit ICD-10 (international classification of diseases, 10th revision) code of the underlying cause, their forms were reassigned to each other (anonymously) for reconciliation. ${ }^{25} \mathrm{~A}$ senior physician adjudicated continuing disagreements. We used relatively non-stringent criteria to define deaths

\begin{tabular}{|c|c|c|c|c|}
\hline Population & Years & Sample size & Data & Source and reference \\
\hline Million Death Study & $2001-3$ & $\begin{array}{l}125000 \text { deaths in } 1.1 \text { million } \\
\text { homes (nationally } \\
\text { representative) }\end{array}$ & $\begin{array}{l}\text { Causes of death by age, sex, } \\
\text { and district }\end{array}$ & Registrar General of India ${ }^{17}$ \\
\hline $\begin{array}{l}\text { Medically certified causes of } \\
\text { death from selected urban } \\
\text { hospitals }\end{array}$ & $1990-2000$ & $\begin{array}{l}\text { About } 300000 \text { annual deaths } \\
\text { in } 300 \text { urban hospitals of } 21 \\
\text { states }\end{array}$ & $\begin{array}{l}\text { Causes of death by age and sex } \\
\text { in urban areas }\end{array}$ & Registrar General of India ${ }^{18}$ \\
\hline Antenatal clinic attenders & $2000-7$ & $\begin{array}{l}1015780 \text { women at public } \\
\text { clinics }\end{array}$ & $\begin{array}{l}\text { HIV and syphilis status, by key } \\
\text { demographic groups in women } \\
\text { aged } 15-34\end{array}$ & $\begin{array}{l}\text { National AIDS Control } \\
\text { Organization }^{6}\end{array}$ \\
\hline $\begin{array}{l}\text { Voluntary counselling and } \\
\text { testing centre attenders }\end{array}$ & $2003-7$ & $\begin{array}{l}2207854 \text { women and } 2405 \\
248 \text { men at public clinics }\end{array}$ & $\begin{array}{l}\text { HIV status by age, sex, and } \\
\text { district in men and women } \\
\text { aged } \geq 15\end{array}$ & $\begin{array}{l}\text { National AIDS Control } \\
\text { Organization }^{6}\end{array}$ \\
\hline
\end{tabular}




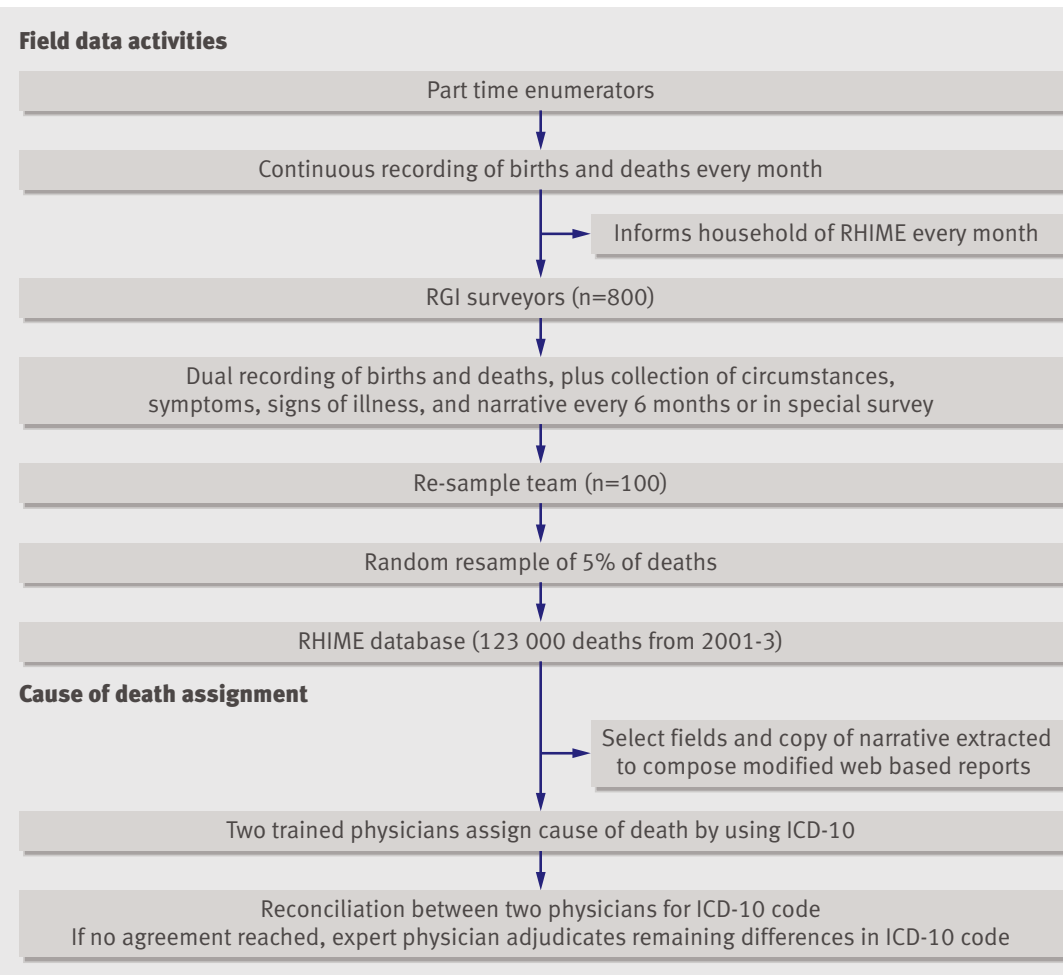

Fig 1| Million Death Study RHIME activities. RGI=Registrar General of India

from AIDS (ICD-10 codes B20-B24, R75), even if only one physician coded the cause as AIDS, if a diagnosis of HIV had been recorded by a physician in the past, or if any key word in the history or narrative included "HIV" or "AIDS."

\section{Methods to estimate HIV as cause of non-AIDS deaths}

HIV infection is a cause of all deaths from AIDS but also the underlying cause of many deaths attributed to other diseases, most notably tuberculosis. ${ }^{1633}$ Previous studies worldwide have shown that HIV infection increases the risk of death from tuberculosis. ${ }^{34-37} \mathrm{We}$ used the following method (one that ensured we did not underestimate deaths from causes other than AIDS attributable to HIV, which we measured directly) to estimate total HIV attributable mortality. Firstly, we quantified the annual age specific probability of death from tuberculosis versus other deaths by using a medically certified cause of death survey of about 0.3 million annual deaths from more than 300 urban hospitals from 1990-2000. ${ }^{18}$ The proportions of deaths from tuberculosis to total deaths fell at all ages among men in the low HIV states and among women in all states (data not shown), but this proportion did not fall among men aged 25-44 years in the high HIV states (fig 2). Next, we assumed that this stagnation in the proportion of deaths from tuberculosis at ages 2544 among men in the high HIV states was due to an excess of HIV attributable mortality from tuberculosis. We quantified this excess by comparing the tuberculosis specific proportional death rates observed in 1990-3 (before HIV infection became common in these states) with those observed in 1994-2000 (when HIV infection spread rapidly). ${ }^{24}$ The upper $99 \%$ confidence limit of this excess was 33.5\% at age 25-34 (and 16.8\% at age 15-59), which we doubled, in keeping with our approach of ensuring minimal underestimation of HIV attributable mortality. Thus $67.0 \%$ of deaths from tuberculosis at age $25-34$ and $33.6 \%$ of those at age 15-59 in our 2001-3 survey were attributable to HIV in the high HIV states.

Thirdly, we applied this maximal excess of HIV attributable mortality from tuberculosis to three other causes that may either have HIV infection as an underlying cause or mimic death from AIDS: fever of unknown origin, lower respiratory infections, and lymphoma or leukaemia. Fourthly, HIV may well raise death rates from various other diseases, in part through extrapulmonary tuberculosis, ${ }^{33}{ }^{35}$ and the underlying cause of death is misclassified with the RHIME method. ${ }^{20-24}$ To account for other HIV attributable deaths from medical causes or injuries not likely to be caused by HIV, we applied the upper 99\% confidence limit of the HIV prevalence among adults aged 15-49 in the high HIV states tested for HIV in 2005/6 to the remaining deaths. ${ }^{12}$ Finally, we applied the observed ratio between HIV attributable deaths due to AIDS and HIV attributable deaths due to the non-AIDS causes noted above in the high HIV states to the absolute numbers of AIDS deaths observed directly in the low HIV states and among men and women separately. The logic was that the relation between HIV attributable deaths due to AIDS and HIV attributable deaths not due to AIDS increases or decreases on the basis of the prevalence of HIV in the population, as seen in African countries. ${ }^{2728}$

\section{Absolute death rates}

The Sample Registration System enumeration of individual deaths slightly underestimates the overall mortality of Indian adults, ${ }^{3839}$ and our survey missed about $12 \%$ of the enumerated deaths because of out-migration or because no relative could be found. Thus, using methods described earlier, ${ }^{20}$ we used WHO estimates of age specific mortality (irrespective of cause) in India for 2004 and partitioned these deaths across states in proportion to the average of Sample Registration System death rates for 2003-4. ${ }^{170}$ To these state specific total deaths, we applied the age and cause specific proportions from our study.

\section{Geographic comparisons with HIV prevalence in clinic populations}

We compared mortality from AIDS in the districts of the four states in south India with HIV sentinel surveillance results. The sentinel surveys tested 1015780 women aged 15-34 between 2000 and 2007 nationally through sequential, unlinked, and anonymous testing for HIV among pregnant women attending public antenatal clinics between August and November of every year. ${ }^{6}$ District level data came from self referred attenders of voluntary counselling and testing centres aged 15 years and above from 2003 to 2007 (2 207854 


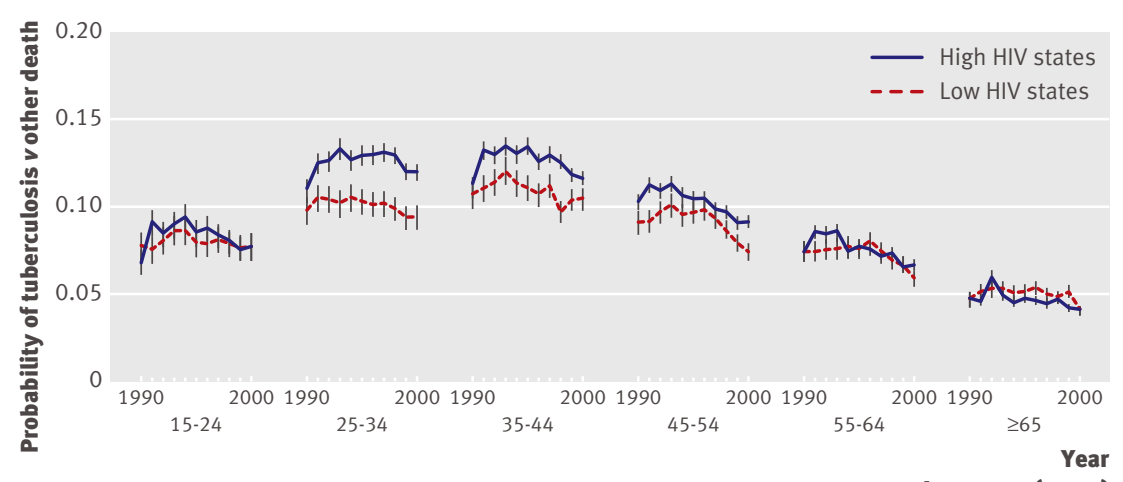

Age group (years)

\begin{tabular}{|l|c|c|}
\hline $\begin{array}{l}\text { Age group } \\
\text { (years) }\end{array}$ & \begin{tabular}{c} 
Difference in probability of tuberculosis v other deaths for $\mathbf{2 0 0 0} \mathbf{~} \mathbf{1 9 9 0}$ (P value) \\
\hline $15-24$
\end{tabular} High HIV states & Low HIV states \\
\hline $25-34$ & $13 \%(0.61)$ & $-1 \%(0.60)$ \\
\hline $35-44$ & $9 \%(0.64)$ & $-4 \%(0.04)$ \\
\hline $45-54$ & $4 \%(0.44)$ & $-2 \%(0.08)$ \\
\hline $55-64$ & $-11 \%(<0.01)$ & $-18 \%(0.03)$ \\
\hline 265 & $-9 \%(0.01)$ & $-21 \%(0.03)$ \\
\hline
\end{tabular}

Fig 2 Age specific trends in probability of death from tuberculosis versus other diseases among urban men aged 15 years or older, 1990-2000. The age specific HIV attributable percentage of deaths from tuberculosis in men in India in the high HIV states in 1994-2000 was $23.5 \%$ ( $99 \% \mathrm{Cl} 13.6 \%$ to $33.5 \%)$ at age $25-34$ and $11.8 \%(6.8 \%$ to $16.8 \%)$ at age $15-59$

women; 2405248 men). HIV testing followed WHO recommended methods for screening in developing countries, using one highly sensitive enzyme linked immunosorbent assay (ELISA), with positive results confirmed by a second ELISA. ${ }^{41}$ Details of the laboratory and quality methods are published. ${ }^{42}$

\section{Statistical methods}

We estimated the relation of the age specific HIV prevalence $(\mathrm{P})$ to $\mathrm{HIV}$ attributable mortality in two ways. Firstly, we used the formula $\mathrm{P}=1 /(((\mathrm{R} / \mathrm{M})+1-\mathrm{R}))$, where $\mathrm{R}$ is the ratio of mortality of HIV infected versus HIV uninfected adults and $M$ the proportion of all

Table 2 | Characteristics of deaths from AIDS (ICD-10 codes B20-B24) at age 15-59 by sex, from 1.1 million nationally representative homes in India, 2001-3. Values are numbers (percentages) unless stated otherwise

\begin{tabular}{lccc} 
Characteristic & Men $(\mathbf{n = 3 7 0 )}$ & Women $(\mathbf{n = 9 8 )}$ & Total ( $\mathbf{n = 4 6 8 )}$ \\
$\begin{array}{l}\text { Mean age (years) } \\
\text { Residence: }\end{array}$ & 35.5 & 35.2 & 35.5 \\
\hline Rural & $299(81)$ & $88(90)$ & $387(83)$ \\
\hline Urban & $71(19)$ & $10(10)$ & $81(17)$ \\
\hline Education: & & & \\
\hline Illiterate or below primary & $125(34)$ & $58(59)$ & $183(39)$ \\
\hline Primary or higher & $245(66)$ & $40(41)$ & $285(61)$ \\
\hline Religion: & & & \\
\hline Hindu & $318(86)$ & $86(88)$ & $19(4)$ \\
\hline Muslim & $16(4)$ & $3(3)$ & $25(5)$ \\
\hline Christian & $20(5)$ & $5(5)$ & $20(4)$ \\
\hline Others or unknown & $16(4)$ & $4(4)$ & \\
\hline
\end{tabular}

Results exclude people with unknown status for age, religion, or education. deaths attributable to HIV, with the accompanying $99 \%$ confidence interval, which is based on M. ${ }^{16}$ The values for $\mathrm{R}$ were based on a cohort study of HIV infected adults in Mumbai and clinical studies in other parts of India, ${ }^{29-32}$ divided by all cause death rates. $^{43}$ Secondly, we calculated mortality estimates on the basis of the assumption of a Weibull survival distribution with a median survival of 10 years. ${ }^{27} \mathrm{We}$ used the direct method to standardise annual HIV prevalences to the 2000-7 age distribution of the national antenatal clinic study population. ${ }^{44}$ Spatial representation of prevalences in antenatal clinics and voluntary counselling and testing centres used empirical Bayes smoothing. ${ }^{45}$ Isopleth maps used ordinary kriging of (geo-located) point estimates.

\section{RESULTS}

HIV attributable mortality from AIDS

As of July 2009, 132626 death records were available for all ages, of which $92.7 \%$ (122 913) were coded by two physicians. The exclusions resulted from operational problems with the records $(4.9 \% ; 6498)$ and missing age, sex, or other information needed for a final diagnosis $(2.4 \% ; 3215)$. A probable cause (excluding ill defined causes and senility) was assigned to $96 \%$ (36 517) of the 38068 deaths at ages 15-59 years.

Table 2 gives the summary results for the 468 deaths that were recorded as due to AIDS in our study. More than three quarters $(n=353)$ of deaths from AIDS occurred in the high HIV states, about four fifths (370) occurred in men, and more than two fifths (183) occurred among illiterate adults. About 86\% (404) of deaths from AIDS occurred among Hindus. The percentage of deaths from AIDS among Muslims (4\%), who constitute $12 \%$ of the Indian population, was disproportionately low, perhaps reflecting male circumcision status. ${ }^{46}$ About 85\% (398) of deaths from AIDS had an earlier diagnosis of HIV by a physician, and analyses restricted to this subgroup showed similar distributions by state, sex, education, and religion (data not shown).

Adults who died from AIDS more often had a history of weight loss $(46 \%)$ than did adults who died from tuberculosis $(28 \%)$ or from other causes $(4 \%)$ (table 3 ). Diarrhoea was also more common among people who died from AIDS (25\%) than among those who died from tuberculosis or other diseases; fever was equally common among those who died from AIDS and tuberculosis. Deaths from both AIDS and tuberculosis more commonly occurred at home than did deaths from other causes. The prevalence of smoking tobacco was similar among men who died from AIDS and tuberculosis, but alcohol use was more common among men who died from AIDS than in those who died from tuberculosis. Few women in the study smoked or drank alcohol.

HIV attributable mortality from diseases other than AIDS Men, but less so women, showed a distinct age pattern for deaths from AIDS, peaking at age 25-34 (fig 3) with a similar peak for deaths from tuberculosis at this age. 
Table 3|Symptoms, place of death, and smoking/drinking history (men) among people who died from AIDS, tuberculosis, and other causes, ages 15-59 years. Values are numbers (percentages)

\begin{tabular}{lccc} 
Characteristic & $\begin{array}{c}\text { Deaths from AIDS* } \\
(\mathbf{n}=\mathbf{4 6 8})\end{array}$ & $\begin{array}{c}\text { Deaths from tuberculosis } \\
(\mathbf{n = 4 8 7 7 )}\end{array}$ & $\begin{array}{c}\text { Other deaths } \\
(\mathbf{n}=33 \text { 788) }\end{array}$ \\
\begin{tabular}{l} 
Symptoms \\
\hline Fever
\end{tabular} & $291(62)$ & $2868(59)$ & $6543(19)$ \\
\hline Diarrhoea & $117(25)$ & $94(2)$ & $1936(6)$ \\
\hline Cough & $150(32)$ & $3936(81)$ & $3144(9)$ \\
\hline Mouth sores or patches & $25(5)$ & $3(0.1)$ & $71(0.2)$ \\
\hline Weight loss & $216(46)$ & $1375(28)$ & $1316(4)$ \\
\hline Place of death & $372(80)$ & $3868(79)$ & $7081(21)$ \\
\hline Home & $58(12)$ & $661(14)$ & \\
\hline Hospital/health facility & & $1930 / 3195(60)$ & $9408 / 20378(46)$ \\
\hline Smoking/drinking (men only) & $224 / 370(61)$ & $1364 / 3195(43)$ & $6584 / 20378(32)$ \\
\hline Smoked tobacco & $221 / 370(60)$ &
\end{tabular}

We did not detect any excess at age 25-44 in deaths attributed to cancers, digestive disease, or other diseases (data not shown), as might have been produced by HIV induced extrapulmonary tuberculosis. ${ }^{35}$ Table 4 gives estimates of the number of HIV attributable deaths by cause in India at age 25-34 and of the total HIV attributable deaths at age 25-34 and 15-59 for 2004. At age 25-34, 8.1\% (99\% confidence interval $5.0 \%$ to $11.2 \%$ ) of all deaths were attributable to HIV. AIDS accounted for $40 \%$ and tuberculosis for $26 \%$ of HIV attributable deaths at age 25-34. The geographic and sex related patterns at age 15-59 were similar to those seen at age 25-34. HIV attributable deaths accounted for $3.2 \%(1.9 \%$ to $4.6 \%)$ of deaths at age 15-59 or, in absolute numbers, about 100000 (59000 to 140000$)$ deaths. The proportion of total deaths attributable to HIV was significantly larger in the high HIV states ( $9 \%$ of all deaths) than in the low HIV states $(1 \%)$ and was larger in men $(4.3 \%)$ than in women $(1.6 \%)$.

\section{Relation of AIDS mortality to HIV prevalence}

Figure 4 shows the geographic distribution of deaths from AIDS as a percentage of all deaths at age 15-49 in the districts of the southern states of Andhra Pradesh, Maharashtra, Karnataka, and Tamil Nadu. The districts where deaths from AIDS represented more than $10 \%$ of the total deaths at ages $15-49$ were chiefly in the same districts where prevalence of HIV in pregnant women aged 15-49 attending public antenatal clinics was above $2 \%$ in 2003. Considerable local variation in deaths from AIDS and HIV infection existed across districts. Notable "hot spots" in 2003 for HIV infection and AIDS mortality were in the Mumbainorthern Karnataka corridor and along the eastern highway areas of Andhra Pradesh.

Further spatial analyses in the high HIV states showed broad geographic declines in HIV prevalence between 2003 and 2007 among pregnant women aged 15-24 (fig 5). Among self referred (and hence more biased) voluntary counselling and testing centre populations, HIV prevalence declined between 2003 and
2007 among both women (relative decline 42.5\%, $99 \%$ confidence interval $41.2 \%$ to $44.5 \%$ ) and men $(55.1 \%, 53.8 \%$ to $56.9 \%)$. The number of "hot spots" faded continuously and similarly in antenatal clinic and voluntary counselling and testing centre populations between 2003 and 2007. Seropositivity in voluntary counselling and testing centres attenders increased in 2007 near Mumbai (formerly Bombay), but not in young pregnant women, perhaps owing to expansion of the antiretroviral treatment programme in $2006 .{ }^{47}$

\section{Trends in all cause mortality and HIV prevalence}

Any major increase in HIV infection should have increased all cause mortality in young adults, as has occurred in Africa, ${ }^{48}$ because death rates at young ages are low and competing causes are few. In the southern high HIV states in 2003, total death rates at age 25-34 varied from 2 to 3 per 1000 (compared with about 6-8/1000 at all ages), ${ }^{40}$ and the leading causes of death in men in this age group were, in decreasing order, intentional and unintentional injuries, cardiovascular disease, tuberculosis, AIDS, digestive diseases, and cancers. ${ }^{17}$ Increases in all cause mortality among men aged 25-34 occurred between 1997 and 2002 (fig 6), but the increases stopped by 2002 and death rates have declined since. Increases in HIV attributable deaths (particularly from AIDS and tuberculosis) probably accounted for the 1997-2002 increases, although competing mortality from increases in intentional injuries cannot be ruled out. ${ }^{17}$ In contrast, all cause mortality in women aged $25-34$ fell by about 20\% between 1997 and 2007.

In the high HIV states, the age standardised prevalence of HIV among pregnant women aged 15-24 fell
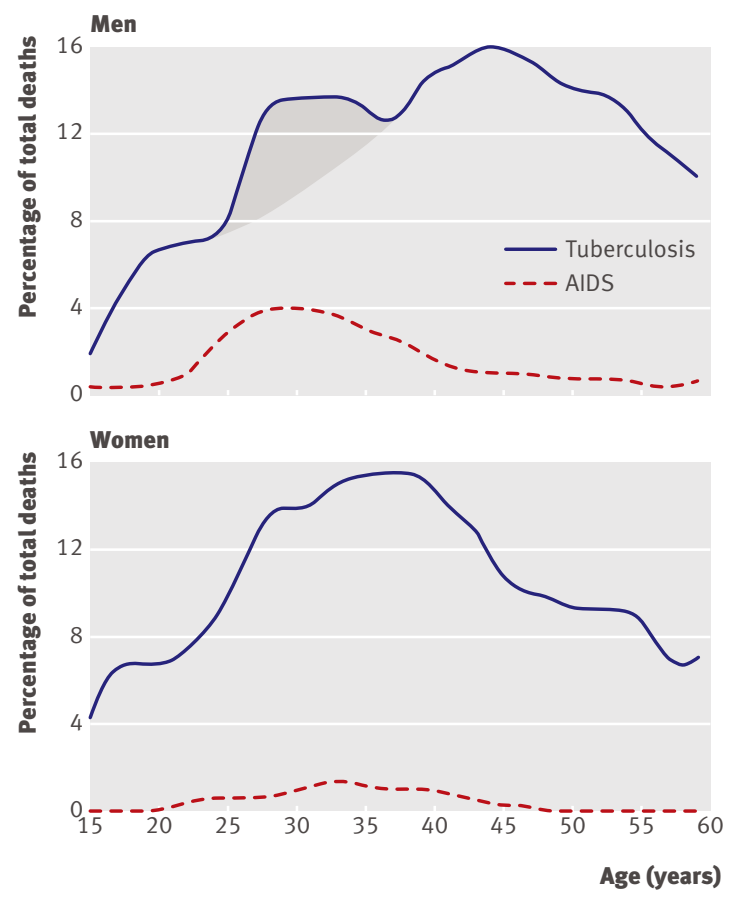

Fig 3 Age distribution of deaths from AIDS and tuberculosis by sex at age 15-59 years in 2001-3 in India 
from $1.96 \%$ in 2000 to $0.74 \%$ in 2007 (relative decline $62.2 \%, 53.8 \%$ to $70.7 \%$ ) (fig 7). Declines were comparable when we restricted analyses to the 25 antenatal clinic sites open continuously for eight years (relative decline $47.8 \%, 27.4 \%$ to $68.2 \%$ ). Declines varied little by literacy, migrant status, or residency (data on CGHR website at http://cghr.org/ecological_page. $\mathrm{htm})^{89}$ and were similar after exclusion of Tamil Nadu (where interventions began earliest among the high HIV states $^{4}$ ) (data not shown). We also saw declines among pregnant women aged 25-34 (data not shown). In the low HIV states, age standardised HIV prevalence estimates were below $0.5 \%$ in all age groups and did not change significantly between 2000 and 2007 among pregnant women aged 15-24 or 2534. Declines in both regions seem not to be due to changes in the type of women being tested in the antenatal clinic sites (more data on CGHR website). ${ }^{89}$

\section{National HIV prevalence estimates}

Table 5 compares estimates of HIV prevalence at age 15-49 and absolute numbers of adults infected in 2004 on the basis of our mortality data with the Weibull estimates of national mortality and with the results of direct testing of adults in a nationally representative household survey in 2005/6. ${ }^{12}$ All three estimates are comparable, ranging from $0.25 \%$ to $0.28 \%$ with overlapping confidence intervals.

\section{DISCUSSION}

HIV attributable deaths

Our estimates of mortality in India suggest that about 100000 adults (range 59000-140000) aged 15-59 years died from HIV infection in 2004. Our

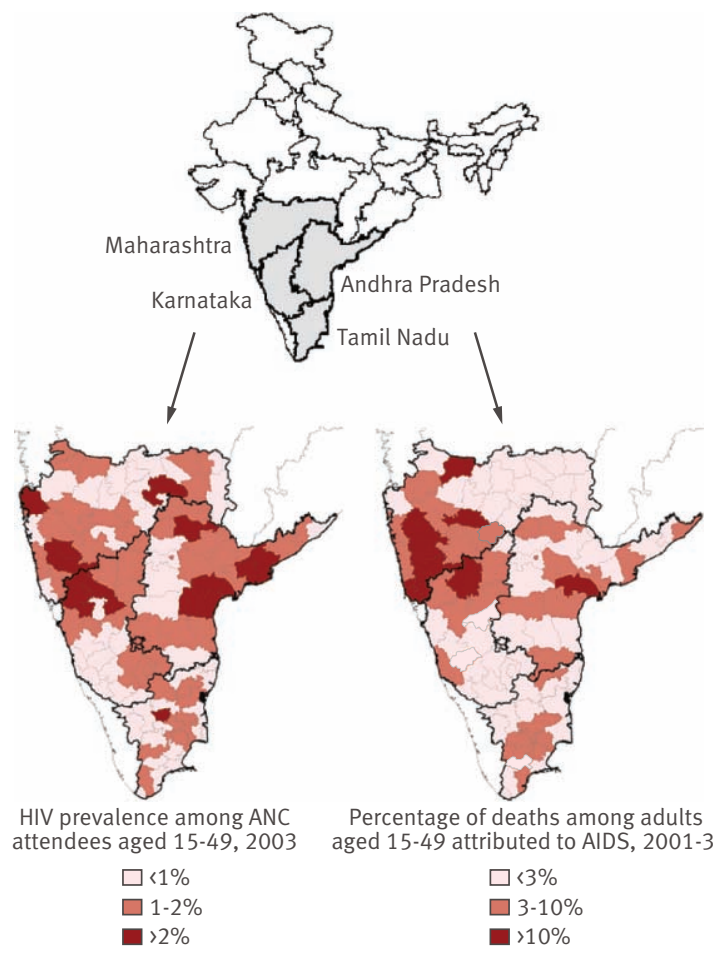

Fig $4 \mid$ HIV prevalence among women aged $15-49$ years in 2003 and AIDS as a percentage of deaths at age 15-49 among districts in the four southern states in 2001-3. 115 districts (using 2001 census boundaries) are included for antenatal clinic (ANC) sites; 94 districts (using 1991 census boundaries) are included for mortality

results differ from WHO's 2003 estimate of at least 270000 deaths,${ }^{14}$ but they are broadly consistent with earlier indirect estimates of mortality in India and with WHO's revised estimate of 127000 deaths from HIV

Table 4 | Estimates of numbers of deaths in adults directly and indirectly attributable to HIV, subdivided by ages $25-34$ and 15-59 years and by disease group, state, and sex, India, 2004

\begin{tabular}{|c|c|c|c|c|c|c|}
\hline & \multicolumn{5}{|c|}{ Number attributable to HIV/total (in thousands) } & \multirow{3}{*}{$\begin{array}{c}\% \text { of HIV attributable } \\
\text { deaths }\end{array}$} \\
\hline & \multicolumn{2}{|c|}{ By state, both sexes } & \multicolumn{3}{|c|}{ India, by sex } & \\
\hline & High HIV states* & Low HIV states* & Men & Women & Both & \\
\hline \multicolumn{7}{|c|}{ Age $25-34$, by cause of death $\dagger$} \\
\hline AIDS & $13.9 / 13.9$ & $2.4 / 2.4$ & $12.8 / 12.8$ & $3.5 / 3.5$ & $16.3 / 16.3$ & 40 \\
\hline Tuberculosis & $8.9 / 13.4$ & $1.5 / 50.6$ & $8.2 / 36.6$ & $2.2 / 27.4$ & $10.4 / 64.0$ & 26 \\
\hline Fever of unknown origin & $6.7 / 10.1$ & $1.2 / 26.3$ & $6.2 / 18.7$ & $1.7 / 17.7$ & $7.9 / 36.4$ & 19 \\
\hline $\begin{array}{l}\text { Lower respiratory } \\
\text { infections }\end{array}$ & $0.1 / 0.2$ & $0.02 / 3.1$ & $0.1 / 1.9$ & $0.02 / 1.4$ & $0.1 / 3.3$ & 0.3 \\
\hline $\begin{array}{l}\text { Lymphomas or } \\
\text { leukaemia }\end{array}$ & $3.2 / 4.8$ & $0.6 / 17.2$ & $2.9 / 9.6$ & $0.8 / 12.4$ & $3.8 / 22.0$ & 9 \\
\hline Other causes & $1.7 / 96.4$ & $0.3 / 260.7$ & $1.6 / 213.6$ & $0.4 / 143.5$ & $2.0 / 357.1$ & 5 \\
\hline \multicolumn{7}{|c|}{ All HIV attributable causes/total deaths $(\%, 99 \% \mathrm{Cl})$} \\
\hline Age $25-34$ & $\begin{array}{c}34.5 / 138.8 \\
(24.9,19.2 \text { to } 30.5)\end{array}$ & $\begin{array}{c}6.0 / 360.3 \\
(1.7,0.1 \text { to } 5.4)\end{array}$ & $\begin{array}{c}31.8 / 293.2 \\
(10.8,6.8 \text { to } 14.9)\end{array}$ & $\begin{array}{c}8.7 / 205.9 \\
(4.2,0.1 \text { to } 9.1)\end{array}$ & $\begin{array}{c}40.5 / 499.0 \\
(8.1,5.0 \text { to } 11.2)\end{array}$ & 100 \\
\hline Age 15-59 & $\begin{array}{c}78.3 / 868.0 \\
(9.0,6.5 \text { to } 11.5)\end{array}$ & $\begin{array}{c}21.3 / 2211.9 \\
(1.0,0.1 \text { to } 2.5)\end{array}$ & $\begin{array}{c}78.9 / 1821.9 \\
(4.3,2.6 \text { to } 6.0)\end{array}$ & $\begin{array}{c}20.7 / 1258.0 \\
(1.6,0.1 \text { to } 3.8)\end{array}$ & $\begin{array}{c}99.6 / 3079.9 \\
(3.2,1.9 \text { to } 4.6)\end{array}$ & 100 \\
\hline
\end{tabular}

*High HIV states are Andhra Pradesh, Karnataka, Maharashtra, Tamil Nadu, Manipur, and Mizoram; remainder are low HIV states; Nagaland was excluded.

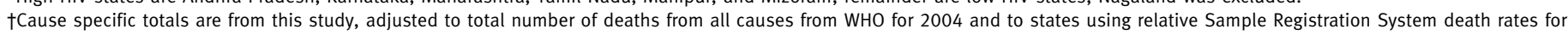

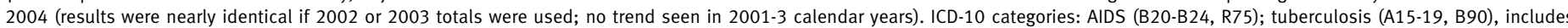

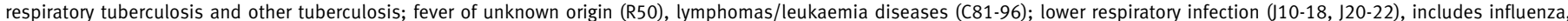

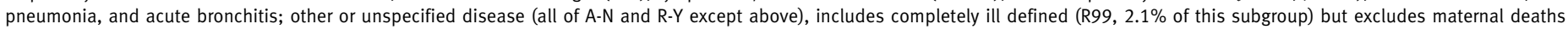
(0) in women. 
Table 5 Estimated prevalence of HIV at ages $15-49$ years in India, by three different methods

\begin{tabular}{|c|c|c|}
\hline Method/year & $\begin{array}{l}\% \text { prevalence } \\
(99 \% \mathrm{Cl})\end{array}$ & $\begin{array}{l}\text { Millions of adults } \\
\text { infected }(99 \% \mathrm{Cl})\end{array}$ \\
\hline Mortality based prevalence, Million Death Study, 2004 & $0.26(0.13$ to 0.39$)$ & $1.49(0.75$ to 2.19$)$ \\
\hline $\begin{array}{l}\text { Ratio of prevalence to mortality, based on survival } \\
\text { function, using national mortality totals for } 2004\end{array}$ & 0.25 (0.13 to 0.31$)$ & $1.42(0.71$ to 1.76$)$ \\
\hline HIV testing, NHFS-3, 2005-6 & $0.28(0.23$ to 0.35$)$ & $1.59(1.31$ to 1.99$)$ \\
\hline
\end{tabular}

NHFS=national family health survey.

See web appendix B for methodological note.

in 2004 that takes into account the 2005/6 HIV survey results. ${ }^{154950}$ Notwithstanding uncertainty in our estimation methods, HIV seems to have accounted for about 1 in 12 deaths at age 25-34 in India in 2004 The markedly higher proportion of HIV attributable deaths in the high HIV states than in the low HIV states was consistent with the four or five times higher prevalence of HIV among pregnant women in the high HIV states. $^{6}$

Since 1995, short course treatment of tuberculosis has expanded more in the high HIV states than in the low HIV states. ${ }^{51}$ Despite this, HIV infection probably contributed to a marked stagnation between 1990 and

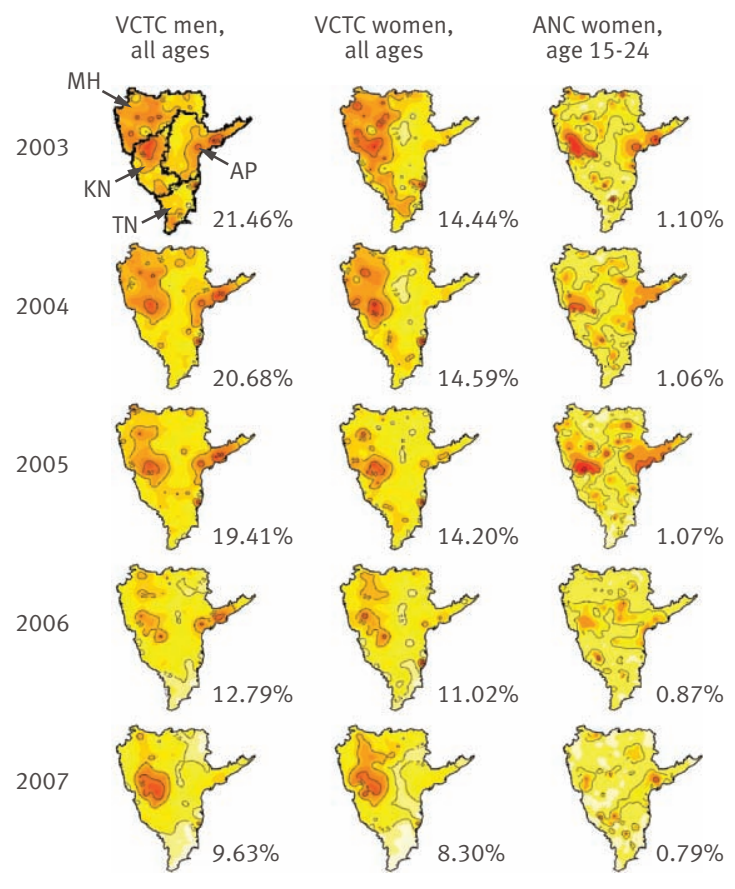

Fig 5 | Spatial distribution of HIV prevalence among antenatal clinic (ANC) and voluntary counselling and testing centre (VCTC) attenders in high HIV states, 2003-7. This procedure interpolates prevalence rates between specific point locations to generate a continuous surface..$^{45}$ District aggregated VCTC prevalence estimates were geo-located to the district's centroid (geometric centre). HIV prevalence estimates were geo-located to the city/town of each testing site. For VCTC maps, isolines are drawn at $40 \%, 30 \%, 20 \%$, and $7.5 \%$ (red to yellow). VCTC maps for all years use same colour scale. For ANC maps, isolines are drawn at $5 \%, 4 \%, 2 \%$, and $1 \%$ (red to yellow). ANC maps for all years use same colour scale. Percentages are overall prevalence. AP=Andhra Pradesh, $\mathrm{KN}=$ Karnataka, $\mathrm{MH}=$ Maharashtra, $\mathrm{TN}=$ Tamil Nadu. District boundaries are as in fig 4
2000 in the proportion of mortality from tuberculosis compared with total mortality in men in urban areas aged 25-44 in the high HIV states, to increases in all cause mortality at age 25-34 between 1997 and 2002, and to a corresponding age specific excess in deaths from tuberculosis among men in our 2001-3 mortality survey (fig 2).

Expanded antiretroviral treatment cannot explain our results; the cumulative number of adults using antiretroviral was only 57000 as of 2006 (only a modest increase from earlier years), 180000 as of 2008, and about 250000 as of $2009 .{ }^{47}$ In the future, AIDS treatment may well result in increased survival of people with HIV infection and hence result in a higher overall prevalence of HIV. However, as long as coverage with antiretroviral treatment remains low (below a third if we compare the maximal coverage of 250000 on treatment in 2009 with the lowest estimate of 0.75 million HIV infected adults in 2004), trends in HIV prevalence will largely reflect (with delay) trends in incidence of infection.

\section{Implications for national prevalence and surveillance}

Systematic data on incidence of HIV or deaths from AIDS over prolonged periods to accurately measure prevalence of HIV are not available in India or most low income countries. ${ }^{10}$ Our estimates of prevalence of HIV based on mortality depended on the mortality ratio between HIV infected and uninfected people, but our ratio is plausible and consistent with ratios observed elsewhere. ${ }^{16}$ Our mortality based estimate of HIV prevalence of approximately $0.26 \%$ at age 15 49 is consistent with the $0.28 \%$ estimate from nationally representative testing for HIV in $2005 / 6,{ }^{12}$ as well as with our observed ratio between prevalence and mortality. Collectively, all three methods suggest that India had about 1.4 to 1.6 million HIV infected adults aged 15-49 in 2004-6, well below the official estimate of 2.3 million (range 1.9-3.0 million) in this age group. ${ }^{1}$ Indeed, our estimates of HIV prevalence might well be construed as upper limits.

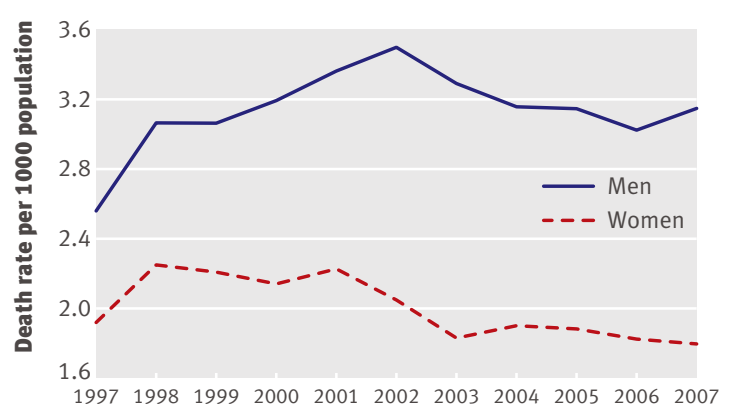

Year

Fig 6 | Trends in all cause mortality rates at ages 25-34 in southern states, 1996-2007. Sample Registration System death rates are calculated on basis of two year rolling averages starting with 1996 death rates, weighted by population size for Andhra Pradesh, Karnataka, Maharashtra, and Tamil Nadu 


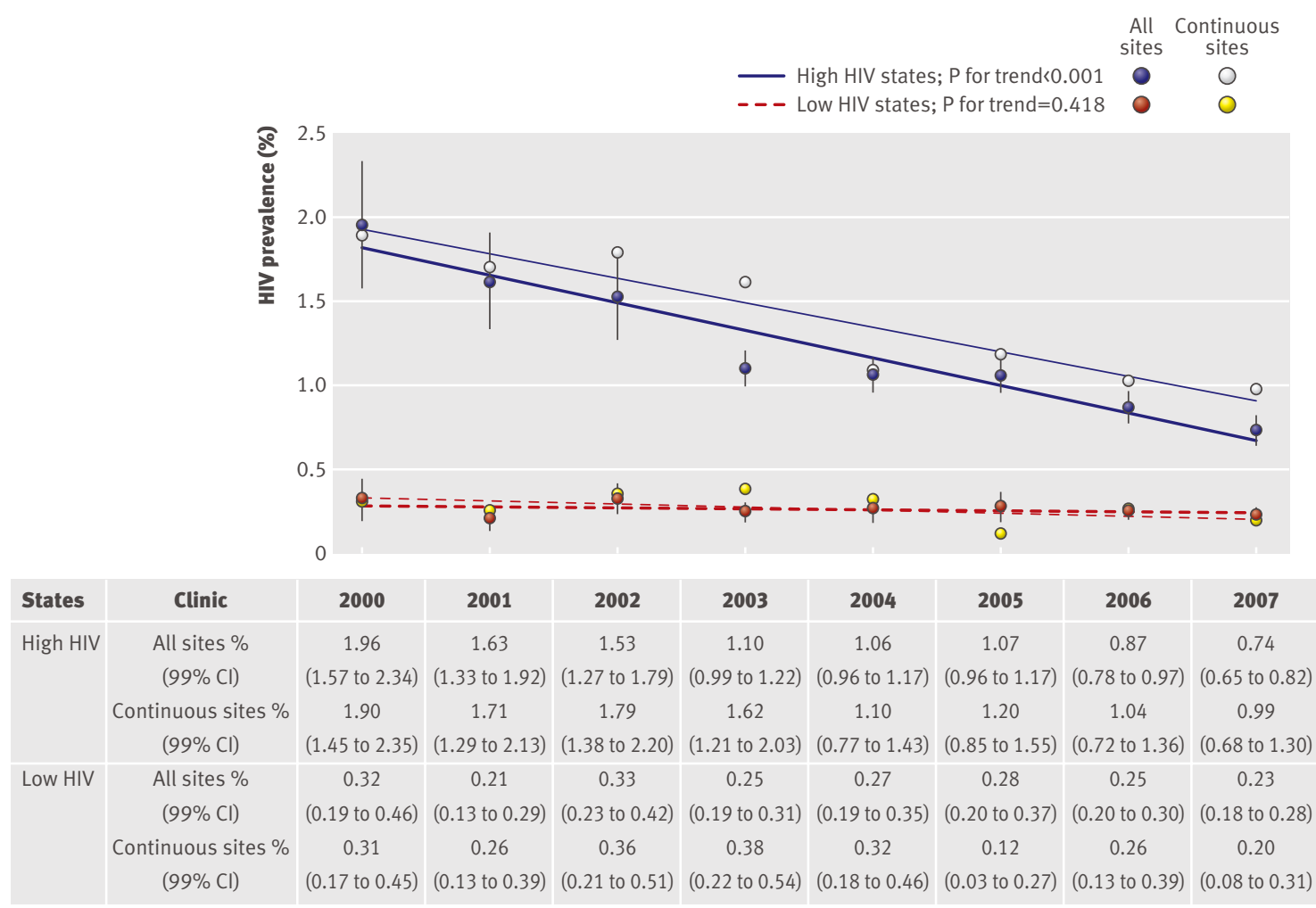

Fig 7| Trends in HIV prevalence among pregnant women aged 15-24 from 2000-7 in high and low HIV states. Low HIV states exclude northeast states (about 1.2\% of India's population), as injecting drug use dominates transmission in this region and may not be reflected well in trends of HIV in pregnant women. HIV prevalence estimates are age standardised to aggregate study population, 2000-7. All trend tests are adjusted for age, literacy, urban/rural residence, migrant status, state, clinic type, and year. Annual number of antenatal clinic attenders of all ages tested each year (2000-7) in high HIV states were 9599, 12 641, 15030, 59 404, 63105, 63240, 64 283, and 67 265; numbers in low HIV states were 12 386, 22 386, 25 764, $44790,26704,26248,68207$, and 71356 . Numbers of surveillance sites in high HIV states were 36, 48, 54, 220, 234, 234, 235, and 242 (with 25 continuous sites); numbers in low HIV states were 56, 100,114, 215, 118, 119, 339, and 345 (with 45 continuous sites)

The National AIDS Control Organization's official national HIV prevalence (range $0.36-0.41 \%$ at age 15 49) involved an upward adjustment to the recorded prevalence in the 2005/6 HIV survey to account for non-sampled populations, ${ }^{1011}$ such as migrant men, that are presumed to be at higher risk of HIV. However, this somewhat arbitrary upward adjustment may have overestimated actual prevalence, especially as use of condoms with non-regular partners (chiefly commercial sex) rose sharply between 2001 and 2006 among men at high risk. ${ }^{5253}$

The increases in overall mortality among men aged 25-34 levelled off by 2002 and subsequently fell, and HIV infection in pregnant women fell continuously between 2000 and 2007. This suggests that no major increase in HIV infection has occurred over the past few years (and, moreover, that, unlike in Uganda, ${ }^{4854}$ major increases in mortality do not explain the decreases in HIV prevalence). Indeed, overall HIV prevalence (and probably HIV attributable deaths) may have fallen further since 2004 .

Our study also raises the possibility of monitoring HIV infection and HIV attributable mortality. We suggest four methods to yield important data on prevalence, incidence (at least proxy incidence of prevalent infections in younger adults), and mortality. These are larger and better cohort studies of HIV infected populations on antiretroviral treatment or not, reporting of causes of death by using methods similar to those of the Registrar General of India, ${ }^{17}$ periodic validation of population based HIV testing, ${ }^{10}$ and expanded sentinel surveillance (including voluntary testing sites) with periodic behavioural surveys. In India, and in other low income countries, this routine surveillance system offers low cost, long term, and sustainable monitoring of the evolution of the HIV epidemic and the effectiveness of prevention and treatment services.

\section{Limitations: biases and misclassification}

Our sample was nationally representative of all deaths in India but would tend to miss people who were homeless or living alone when they died; overall, we obtained information on $88 \%$ of all enumerated deaths. Migrant adults would be less likely to be missed in our survey than in the $2005 / 6 \mathrm{HIV}$ survey, ${ }^{12}$ as the Sample Registration System continuously enumerates household membership and death. ${ }^{1940}$ Anecdotal evidence suggests that rural migrants tend to come back to their village to die. Indeed, we found that a greater proportion of the people who died from AIDS had 


\section{WHAT IS ALREADY KNOWN ON THIS TOPIC}

HIV mortality estimates in India for recent years have varied from 270000 to 630000 and have been recently revised by WHO to 127000 deaths for 2004 .

Earlier mortality estimates have drawn on prevalence of HIV, which is unreliable, and not on direct estimates of mortality

National estimates of HIV infected adults aged 15-49 were halved from about 5 million to 2.3 million after a national survey in $2005 / 6$, but this result has not been validated

\section{WHAT THIS STUDY ADDS}

A survey of 1.1 million representative homes found that about 100000 (range 59000 140000 ) adults aged 15-59 died from HIV in 2004

At ages $25-34$ years, about $40 \%$ of these deaths were from AIDS, $26 \%$ were from tuberculosis, and the remainder were from other causes

These results suggest that India had roughly 1.4-1.6 million adults aged 15-49 with HIV infection in $2004-6$, about $40 \%$ below the official estimate

living siblings or parents than did those who died from other causes (data not shown).

We found a reasonably good sensitivity and specificity for both deaths from AIDS and those from tuberculosis in the original survey compared with the resampled causes of deaths, and our results were also comparable to those of earlier validation studies that compared diagnosis of tuberculosis by using the RHIME verbal autopsy technique with that in hospital records. ${ }^{24}$ Moreover, the broad pattern of symptoms for deaths from AIDS, most importantly marked weight loss, was consistent with clinical studies of people with AIDS. ${ }^{1629-32}$ The field workers made no judgment on HIV status, which would tend to discourage reporting of key symptoms by living respondents. Finally, about $85 \%$ of the people who died from AIDS had a medical history of HIV infection. Still, verbal autopsy methods misclassify the underlying causes of some deaths. ${ }^{161719-24}$ Absolute underestimation of HIV attributable deaths would most likely occur if tuberculosis is misclassified with causes of death other than AIDS. Our indirect method to calculate HIV attributable deaths from causes other than AIDS is crude. However, we have consistently erred on the side of overestimation of these proportions. ${ }^{55}$

\section{Conclusion}

HIV attributable death and infection in India is substantial, although lower than previously estimated. Our mortality results are consistent with the reported declines in prevalence of HIV infection between 2000 and 2007.

The Registrar General of India (RGI) established the Sample Registration System (SRS) in 1971, has continued it ever since, and is collaborating with several of the authors on the ongoing Million Death Study. Web appendix A gives a full list of collaborators. All study materials are available freely at www.cghr.org and more details are provided at http:// content.nejm.org/cgi/content/full/NEJMsa0707719/DC1. We thank 0 Bhattacharya, A Laupacis, M Mamdami, and R Peto for providing comments and $\mathrm{O}$ Berke for assistance with graphics. The opinions expressed here are those of the authors and do not necessarily represent those of the National AIDS Control Organization or the RGI. Contributors: PI and the academic partners in India (RGI-CGHR Collaborators) planned the Million Death Study in close collaboration with the office of the RGI. PJ, DK, WS, DGB, and AS did the statistical analyses, with input from NN. PJ and DK developed the HIV attribution method for causes other than AIDS. All authors participated in interpreting the data and writing the manuscript. PJ is the guarantor.

Funding: External funding is from the Fogarty International Centre of the US National Institutes of Health (grant R01 TW05991-01), Canadian Institute of Health Research (CIHR; IEG-53506), International Research Development Centre (grant 102172), and Li Ka Shing Knowledge Institute and Keenan Research Centre at St Michael's Hospital, University of Toronto (unrestricted CGHR support). PJ is supported by the Canada research chair program. PA is supported by supported by a CIHR Banting and Best Canada graduate scholarship. The funding sources had no role in the design or conduct of the study, or in the collection, analysis, or interpretation of the data. PJ had full access to all the data and had final responsibility for the decision to submit for publication.

Competing interests: None declared

Ethical approval: SRS enrolment is on a voluntary basis, and its confidentiality and consent procedures are defined as part of the Registration of Births and Deaths Act, 1969. Oral consent was obtained in the first SRS sample frame. The study has been approved by the review boards of the Post-Graduate Institute of Medical Education and Research, St Michael's Hospital, and the Indian Council of Medical Research's Health Ministry's Screening Committee.

Data sharing: No additional data available.

1 National AIDS Control Organization (NACO). Annual report 2006. NACO, 2006.

2 Kumar R, Jha P, Arora P, Dhingra N. HIV-1 trends, risk factors and growth in India. In: Rao S, ed. National commission on macroeconomics and health background papers: burden of disease in India. Ministry of Health and Family Welfare, 2005:58-74.

3 Venkataramana CB, Sarada PV. Extent and speed of spread of HIV infection in India through the commercial sex networks: a perspective. Trop Med Int Health 2001;6:1040-61.

4 Jha P. Sex, money and ideas: twenty years of battling AIDS in India. Commonwealth Health Minister's handbook. Commonwealth Secretariat, 2008.

5 Jha P, Nagelkerke JD, Ngugi EN, Prasada Rao JV, Willbond B, Moses S, et al. Public health: reducing HIV transmission in developing countries. Science 2001;13;292:224-5.

6 National AIDS Control Organization (NACO), National Institute for Health and Family Welfare. Annual HIV sentinel surveillance 2006 India country report. 2007. www.nacoonline.org/Quick_Links/ Publication/ME and Research Surveillance/ Reports_and_Surveys/ HIV_Sentinel_Surveillance_2006_India_Country_Report/.

7 UNAIDS/WHO Working Group on Global HIV/AIDS and S TI Surveillance. Guidelines for conducting HIV sentinel serosurveys among pregnant women and other groups. World Health Organization, 2003. (UNAIDS/03.49E.)

8 Arora P, Kumar R, Bhattacharya M, Nagelkerke NJ, Jha P. Trends in HIV incidence in India from 2000 to 2007. Lancet 2008;372:289-90.

9 Kumar R, Jha P, Arora P, Mony P, Bhatia P, Millson P, et al. Trends in HIV-1 in young adults in south India from 2000 to 2004 : a prevalence study. Lancet 2006;367:1164-72.

10 Boerma JT, Ghys PD, Walker N. Estimates of HIV-1 prevalence from national population-based surveys as a new gold standard. Lancet 2003;362:1929-31.

11 Pandey A, Reddy DC, Ghys PD, Thomas M, Sahu D, Bhattacharya M, et al. Improved estimates of India's HIV burden in 2006. Indian / Med Res 2009;129:50-8

12 National AIDS Control Organization (NACO), National Institute of Medical Statistics (NIMS). Technical report: India HIV estimates, 2006. 2007. www.nacoonline.org/upload/NACO\%20PDF/Technical \%20Report\%20on\%20HIV\%20Estimation\%202006.pdf.

13 International Institute for Population Sciences (IIPS), ORC Macro. National family health survey 3 (NFHS-3). IIPS, 2006.

14 United Nations Programme on HIV/AIDS (UNAIDS). 2008 report on the global AIDS epidemic. 2008. http://data.unaids.org/pub/ GlobalReport/2008/jc1510_2008_global_report_pp325_358_en. pdf.

15 Mathers C, Boerma T, Fat D. The global burden of disease: 2004 update. World Health Organization, 2008.

16 Lopman BA, Barnabas RV, Boerma JT, Chawira G, Gaitskell K, Harrop T, et al. Creating and validating an algorithm to measure AIDS mortality in the adult population using verbal autopsy. PLoS Med 2006;3:e312.

17 Registrar General of India, Centre for Global Health Research. Causes of death in India in 2001-2003. Government of India, 2009.

18 Registrar General of India. Medically certified causes of death, statistical report: 2000. Government of India, 2005. 
19 Jha P, Gajalakshmi V, Gupta PC, Kumar R, Mony P, Dhingra N, et al. Prospective study of one million deaths in India: rationale, design, and validation results. PLoS Med 2006;3:e18.

20 Jha P, Jacob B, Gajalakshmi V, Gupta PC, Dhingra N, Kumar R, et al. A nationally representative case-control study of smoking and death in India. N Engl J Med 2008;358:1137-47.

21 Gajalakshmi V, Peto R, Kanaka S, Balasubramanian S. Verbal autopsy of 48000 adult deaths attributable to medical causes in Chennai (formerly Madras), India. BMC Public Health 2002;2:7.

22 Gajalakshmi V, Peto R, Kanaka TS, Jha P. Smoking and mortality from tuberculosis and other diseases in India: retrospective study of 43000 adult male deaths and 35000 controls. Lancet 2003;362:507-15.

23 Joshi R, Cardona M, lyengar S, Sukumar A, Raju CR, Raju KR, et al. Chronic diseases now a leading cause of death in rural Indiamortality data from the Andhra Pradesh Rural Health Initiative. Int J Epidemiol 2006;35:1522-9.

24 Kumar R, Thakur JS, Rao BT, Singh MM, Bhatia SP. Validity of verbal autopsy in determining causes of adult deaths. Indian J Public Health 2006;50:90-4

25 Sinha D, Dikshit R, Kumar V, Gajalakshmi V, Dhingra N, Seth J, et al. Technical document VII: health care professional's manual for assigning causes of death based on RHIME household reports. Centre for Global Health Research, University of Toronto, 2006.

26 Jha P. Avoidable mortality in India: past progress and future prospects. Natl Med J India 2002;15(suppl 1):32-6S.

27 Todd J, Glynn JR, Marston M, Lutalo T, Biraro S, Mwita W, et al. Time from HIV seroconversion to death: a collaborative analysis of eight studies in six low and middle-income countries before highly active antiretroviral therapy. AIDS 2007;21(suppl 6):55-63S.

28 Todd J, Balira R, Grosskurth H, Mayaud P, Mosha F, ka-Gina G, et al. HIV-associated adult mortality in a rural Tanzanian population. AIDS 1997;11:801-7.

29 Hira SK, Shroff HJ, Lanjewar DN, Dholkia YN, Bhatia VP, Dupont HL. The natural history of human immunodeficiency virus infection among adults in Mumbai. Natl Med J India 2003;16:126-31.

30 Chacko S, John TJ, Babu PG, Jacob M, Kaur A, Mathai D. Clinical profile of AIDS in India: a review of 61 cases. J Assoc Physicians India 1995;43:535-8.

31 Kumarasamy N, Venkatesh KK, Devaleenol B, Poongulali S, Yephthomi T, Pradeep A, et al. Factors associated with mortality among HIV-infected patients in the era of highly active antiretroviral therapy in southern India. Int I Infect Dis 2009;July24:[epub ahead of print]

32 Sobhani R, Basavaraj A, Gupta A, Bhave AS, Kadam DB, Sangle SA, et al. Mortality and clinical characteristics of hospitalized adult patients with HIV in Pune, India. Indian J Med Res 2007;126:116-21.

33 Sharma SK, Mohan A, Kadhiravan T. HIV-TB co-infection: epidemiology, diagnosis and management. Indian J Med Res 2005;121:550-67.

34 Duarte EC, Bierrenbach AL, Barbosa da Silva J Jr, Tauil PL, de Fatima Duarte E. Factors associated with deaths among pulmonary tuberculosis patients: a case-control study with secondary data. J Epidemiol Community Health 2009;63:233-8.

35 Kingkaew N, Sangtong B, Amnuaiphon W, Jongpaibulpatana J, Mankatittham W, Akksilp S, et al. HIV-associated extrapulmonary tuberculosis in Thailand: epidemiology and risk factors for death. Int) Infect Dis 2009;13:722-9.
36 Swaminathan S, Nagendran G. HIV and tuberculosis in India. J Biosci 2008;33:527-37.

37 Bernabe-Ortiz A. Factors associated with survival of patients with tuberculosis in Lima, Peru. Rev Chilena Infectol 2008;25:104-7.

38 Mari Bhat PN. Completeness of India's sample registration system: an assessment using the general growth balance method. Popul Stud (Camb) 2002;56:119-34.

39 Sivanandan V. An assessment of the completeness of death registration in India over the periods 1975-1978 and 1996-1999 under the generalized population model: an analysis based on SRS data. International Institute for Population Sciences, 2004.

40 Registrar General of India. Sample registration system, statistical report: 2004. Registrar General of India, 2005.

41 Bhore AV, Sastry J, Patke D, Gupte N, Bulakh PM, Lele S, et al. Sensitivity and specificity of rapid HIV testing of pregnant women in India. Int J STD AIDS 2003;14:37-41.

42 National AIDS Control Organization (NACO), Ministry of Health and Family Welfare. Laboratory manual for technicians (ICTCs, PPTCTs, blood banks and PHCS). NACO, 2007.

43 Department of Economic and Social Affairs, United Nations. Demographic yearbook 2006. 58th ed. Department of Economic and Social Affairs, United Nations, 2008.

44 Rothman K, Greenland S, Lash T. Modern epidemiology. 3rd ed. Lippincott Williams and Wilkins, 2008.

45 Berke O. Exploratory disease mapping: kriging the spatial risk function from regional count data. Int J Health Geogr 2004;3:18.

46 Dandona L, Dandona R, Kumar GA, Reddy GB, Ameer MA, Ahmed GM, et al. Risk factors associated with HIV in a populationbased study in Andhra Pradesh state of India. Int J Epidemiol 2008;37:1274-86

47 National AIDS Control Organization (NACO). ART treatment report NACO, 2007.

48 Boerma JT, Nunn AJ, Whitworth JA. Mortality impact of the AIDS epidemic: evidence from community studies in less developed countries. AIDS 1998;12(suppl1):3-14S.

49 Bhattacharya M, Neogi SB. Estimation of mortality due to AIDS-a review. Indian J Public Health 2008;52:21-7.

50 Hira SK, Srinivasa Rao AS, Thanekar J. Evidence of AIDS-related mortality in Mumbai, India. Lancet 1999;354:1175-6.

51 Williams BG, Granich R, Chauhan LS, Dharmshaktu NS, Dye C. The impact of HIV/AIDS on the control of tuberculosis in India. Proc Nat Acad Sci USA 2005;102:9619-24.

52 National AIDS Control Organization (NACO). National baseline high risk and bridge population behavioural surveillance survey-2001: part-1 female sex workers and their clients. Ministry of Health and Family Welfare, Government of India, 2001.

53 National AIDS Control Organization (NACO). National behavioura surveillance survey-2006: female sex workers and their clients. Ministry of Health and Family Welfare, Government of India, 2006.

54 Konde-Lule JK. The declining HIV seroprevalence in Uganda: what evidence? Health Transit Rev 1995;5(suppl):27-33.

55 Raizada N, Chauhan LS, Khera A, Sokhey J, Wares DF, Sahu S, et al. HIV seroprevalence among tuberculosis patients in India, 20062007. PLOS ONE 2008;3:e2970.

Accepted: 26 October 2009 